\title{
Correction to: Charting How Wealth Shapes Educational Pathways from Childhood to Early Adulthood: A Developmental Process Model
}

\author{
Matthew A. Diemer ${ }^{1} \cdot$ Aixa D. Marchand ${ }^{2} \cdot$ Rashmita S. Mistry ${ }^{3}$
}

Published online: 26 February 2020

(c) Springer Science+Business Media, LLC, part of Springer Nature 2020

\section{Correction to: Journal of Youth and Adolescence}

https://doi.org/10.1007/s10964-019-01162-4

The original article has been published with missed correction where the color key indicators should not be present for Figs 2 and 3 as the article is already in grayscale.

The original article has been corrected.

The original article can be found online at https://doi.org/10.1007/ s10964-019-01162-4.

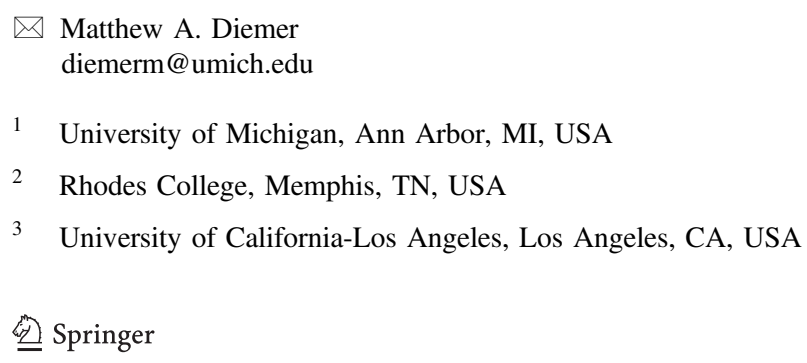




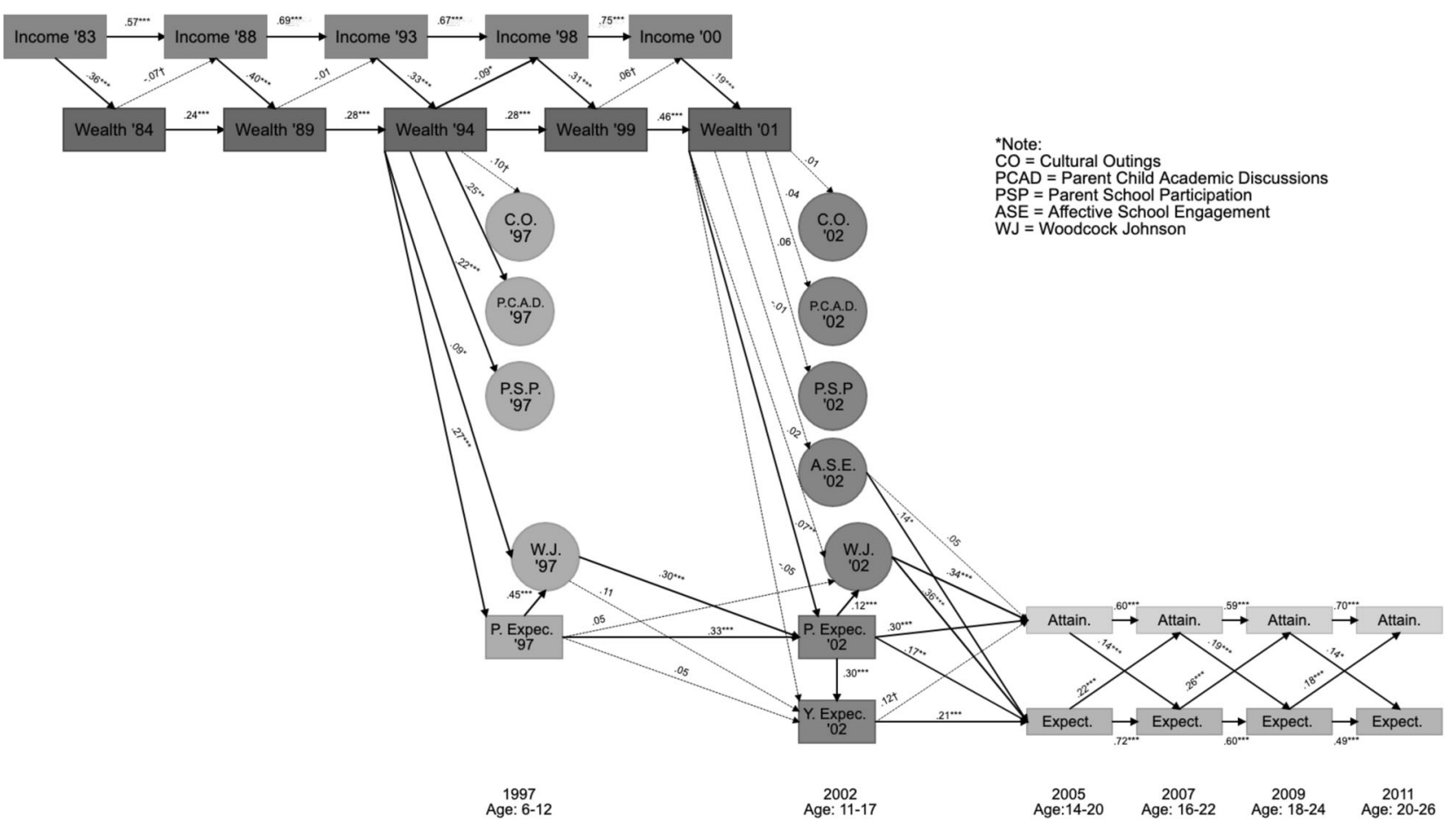

Fig. 2 Model Overview

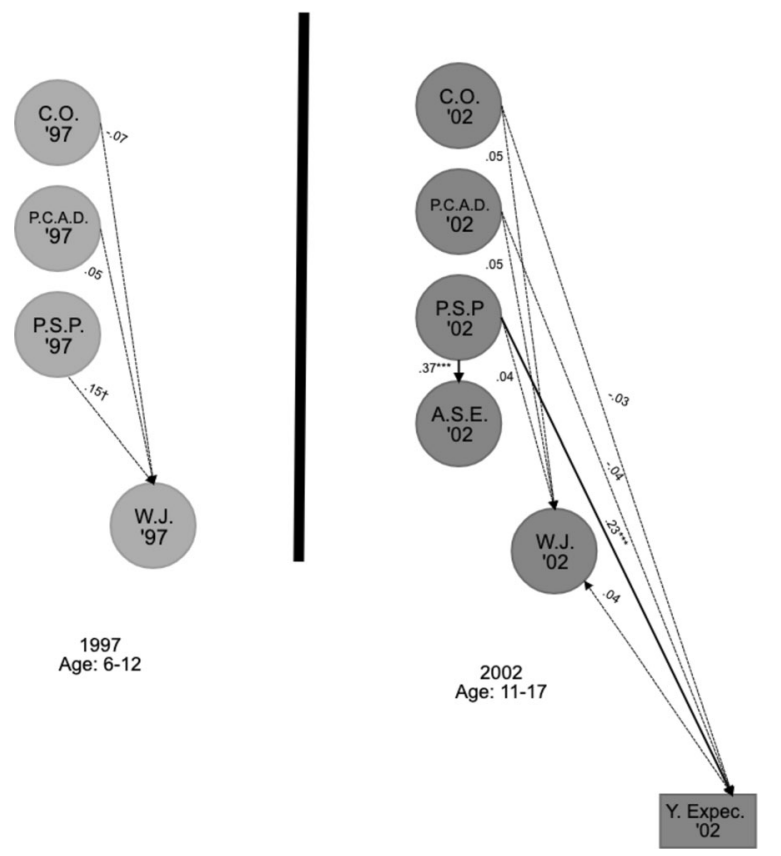

Fig. 3 Specific Relations among Parent/Child Processes and Achievement 